\title{
Designing Multifunctionality into Single Phase and Multiphase Metal-Oxide-Selective Propylene Ammoxidation Catalysts
}

\author{
James F. Brazdil \\ Archer Daniels Midland Company, James R. Randall Research Center, Decatur, IL 62521, USA; \\ james.brazdil@adm.com; Tel.: +1-217-451-2870
}

Received: 5 February 2018; Accepted: 26 February 2018; Published: 2 March 2018

\begin{abstract}
Multifunctionality is the hallmark of most modern commercial heterogeneous catalyst systems in use today, including those used for the selective ammoxidation of propylene to acrylonitrile. It is the quintessential principle underlying commercial catalyst design efforts since petrochemical process development is invariably driven by the need to reduce manufacturing costs. This is in large part achieved through new and improved catalysts that increase selectivity and productivity. In addition, the future feedstocks for chemical processes will be invariably more refractory than those currently in use (e.g., replacing alkenes with alkanes or using $\mathrm{CO}_{2}$ ), thus requiring a disparate combination of chemical functions in order to effect multiple chemical transformations with the fewest separate process steps. This review summarizes the key chemical phenomena behind achieving the successful integration of multiple functions into a mixed-metal-oxide-selective ammoxidation catalyst. An experiential and functional catalyst design model is presented that consists of one or both of the following components: (1) a mixed-metal-oxide-solid solution where the individual metal components serve separate and necessary functions in the reaction mechanism through their atomic level interaction in the context of a single crystallographic structure; (2) the required elemental components and their catalytic function existing in separate phases, where these phases are able to interact for the purposes of electron and lattice oxygen transfer through the formation of a structurally coherent interface (i.e., epitaxy) between the separate crystal structures. Examples are provided from the literature and explained in the context of this catalyst design model. The extension of the model concepts to the design of heterogeneous catalysts in general is also discussed.
\end{abstract}

Keywords: selective oxidation; metal-oxide catalysts; propylene ammoxidation; acrylonitrile; solid solution; coherent interface; epitaxy

\section{Introduction}

The sine qua non of modern commercial catalysts is multifunctionality. Moreover, in order to be both active and selective for a multistep chemical transformation at an industrial scale, it is necessary that the catalysts be multifunctional within several dimensions-chemical composition, solid state chemistry and physical properties. Multifunctionality in catalysts typically means multiple elemental components where each provides a distinct function in the catalytic mechanism that facilitates the transformation of a feed molecule into a product compound by a specific kinetic pathway. To function accordingly, the elemental components need to be in a structural environment that is conducive to co-locating the elements to achieve the seamless interaction of each function. The increased complexity of today's commercial catalysts reflects the myriad requirements for selective chemical transformations. This phenomenon is no more evident than it is in selective oxidation and ammoxidation catalysis. Table 1 summarizes catalyst types according to the number and complexity of the chemical reactions and the requirements of the associated catalyst. 
Table 1. Examples of multifunctionality in catalysts.

\begin{tabular}{|c|c|c|}
\hline Chemical Transformation & Required Chemical Functionality & Prototypical Catalyst Components \\
\hline Hydrogenation & $\begin{array}{l}\text { 1. H-H bond cleavage } \\
\text { 2. } \mathrm{H} \text { insertion }\end{array}$ & $\mathrm{Pt}$, Pd, other Group $8,9,10$ single metals \\
\hline Hydrogenolysis & $\begin{array}{l}\text { 1. H-H bond cleavage } \\
\text { 2. C-C bond cleavage }\end{array}$ & $\begin{array}{c}\mathrm{Pt}, \mathrm{Pd} \text {, other Group } 8,9,10 \text { single and } \\
\text { multiple metals }\end{array}$ \\
\hline Reforming & $\begin{array}{ll}\text { 1. } & \text { H-H bond cleavage } \\
\text { 2. } & \text { C-C bond cleavage } \\
\text { 3. } & \text { Shape selectivity }\end{array}$ & $\begin{array}{l}\text { Group } 8,9,10 \text { bimetallic and } \\
\text { multimetallic supported on zeolites }\end{array}$ \\
\hline Ammonia synthesis & $\begin{array}{ll}\text { 1. } & \mathrm{H}-\mathrm{H} \text { bond } \\
\text { 2. } & \mathrm{N} \equiv \mathrm{N} \text { bond cleavage } \\
\text { 3. } & \mathrm{N}-\mathrm{H} \text { bond formation }\end{array}$ & Single and multimetallic \\
\hline Selective oxidation & $\begin{array}{ll}\text { 1. } & \mathrm{O}=\mathrm{O} \text { bond cleavage } \\
\text { 2. } & \text { Lattice oxygention migration } \\
\text { 3. } & \mathrm{C}-\mathrm{H} \text { bond cleavage } \\
\text { 4. } & \mathrm{O} \text { insertion } \\
\end{array}$ & Multimetal oxides \\
\hline Selective ammoxidation & $\begin{array}{ll}\text { 1. } & \mathrm{O}=\mathrm{O} \text { bond cleavage } \\
\text { 2. } & \text { Lattice oxygen migration } \\
\text { 3. } & \mathrm{C}-\mathrm{H} \text { bond cleavage } \\
\text { 4. } & \mathrm{N}-\mathrm{H} \text { bond cleavage } \\
\text { 5. } & \mathrm{N} \text { insertion }\end{array}$ & Multimetal oxides \\
\hline
\end{tabular}

In addition to the chemical functionalities described in the table, a commercial catalyst will have a number of physical requirements in order to be compatible with their preferred mode of reactor operation, i.e., fixed-bed, trickle-bed or fluid-bed, among others. Among these physical requirements are crush strength, attrition resistance, surface area, pore volume and pore size.

Another critically important functionality for a commercial catalyst, the one that is perhaps the least studied and understood, is stability. Stability from a commercial standpoint means that a catalyst is able to maintain satisfactory activity and selectivity over several thousand hours of operation, has the ability to withstand the shutdown and start-up of the process and the capability to return to satisfactory performance following a deviation from steady-state operating conditions with respect to temperature, flow rate and/or feed composition. This stability in many cases is imparted to a catalytically-active solid phase through the addition of select promoter additives to the overall catalyst formulation. These additives may be incorporated into the structure of the active phase or they may reside as a separate phase from the active phase. In the latter case, a distinct chemical and physical interaction must occur between the additive and active phases in order to impart the desired stability characteristics to the catalyst. The chemical and/or physical interaction may include control of the oxidation state of one or more of the elements of the active phase in the optimal state for the catalyzed reaction. Otherwise, such oxidation state control may ameliorate the conversion of an active phase component to a mobile or volatile state under the reaction conditions, which can result in the loss of the active component or the restructuring of the active phase over time, thus diminishing the overall performance of the catalyst. An example of this in the case of propylene ammoxidation catalysts is the reduction of $\mathrm{Bi}^{3+}$ or $\mathrm{Te}^{4+}$ to a metallic state that has significantly higher vapor pressure than their oxides at the $400{ }^{\circ} \mathrm{C}$ to $450{ }^{\circ} \mathrm{C}$ reaction temperatures. This typical steady-state reaction temperature range is well above the Tamman temperatures $\left(\sim \frac{1}{2}\right.$ melting point in $\left.{ }^{\circ} \mathrm{K}\right)$ for these metals and are thus at temperatures where mobility and volatility become appreciable. $\left(\mathrm{Bi} \mathrm{T}_{\text {melt }}=544^{\circ} \mathrm{K} ; \mathrm{Te}_{\text {melt }}=723^{\circ} \mathrm{K}\right)$. The basis for the stabilizing effect of an additive element may also be physical, serving, for example, as an anchor to an inert support phase (such as silica or alumina), thus preventing the loss of catalytic activity due to the growth of large crystallites via sintering.

The manufacture of acrylonitrile by the selective oxidation of propylene with ammonia (generally referred to as selective ammoxidation) represents one of the largest and commercially most important applications of metal-oxide catalysts, with a worldwide production of around seven million metric 
tons per year ( $7 \mathrm{mte} /$ year). This review will use selective propylene ammoxidation catalysis as a surrogate for a complex catalyst needing multiple chemical functions to work in concert in order to achieve the desired chemical transformation selectively and with high activity.

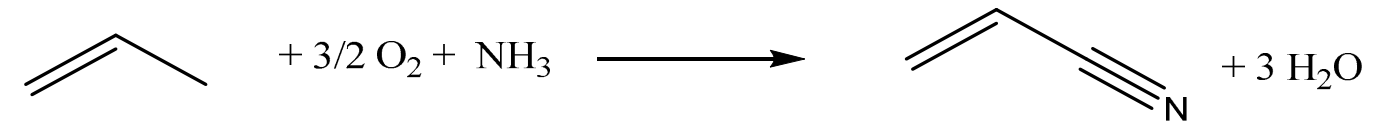

Multifunctionality has been highlighted numerous times in the scientific and patent literature as one of the key requirement for selective oxidation catalysis [1]. This topic has been the subject of several recent review articles [2-5]. However, the understanding and descriptions of the concept of multifunctionality and any associated working mechanisms (as well as several concepts denoted as "pillars" in selective oxidation catalyst construction) have been astutely noted by some as being strictly phenomenological and thus largely lacking in the predictive ability necessary to be used in the practical design of new catalysts or for the improvement of known catalysts a priori [6]. This review will examine the critical characteristics of metal oxides as they pertain to achieving the multifunctionality required for selective oxidation catalysis. Illustrative examples from the scientific and patent literature are used to show how multifunctionality has been achieved in single phase and multiphase metal oxides through the use of solid solutions and interface boundaries, respectively. By analogy, the application of the understanding of the physical basis underlying these key characteristics makes it possible to apply this in a predictive way to the design of new and improved selective oxidation catalysts and potentially other catalyst types and chemical transformations as well. Since many of the earlier excellent reviews were largely written from the perspective of studies of model compounds, rather than by examining information for catalysts closer to those actually used in commercial operation, it is the purpose of this review to examine the subject through the lens of industrial application by including the analysis of select relevant information in the published patent literature. Ambitiously, an effort is made here to render the underlying principles behind multifunctionality applicable to the design of commercial catalysts other than just metal oxides and to chemical transformations other than just selective oxidation.

\section{Models of Multifunctionality in Heterogeneous Selective Oxidation Catalysts}

Since the advent of the modern era of selective hydrocarbon oxidation catalysis, many researchers have sought to describe unifying principles to explain the unique ability of single or multiphase, mixed-metal oxides to catalyze the partial oxidation of reactive alkenes and aromatics, thereby avoiding the most thermodynamically-favored pathway of complete oxidation to $\mathrm{CO}_{2}[7,8]$. To accomplish such a chemically complex surface reaction on a heterogeneous catalyst, it is generally agreed that the metal-oxide catalysts must be able to effect the following functional steps in a seamless reaction sequence [9-11]:

1. H-abstraction from an activated $\mathrm{C}-\mathrm{H}$ bond-allylic (e.g., propylene, butene), aromatic (e.g., toluene, methylpyridine) or from an alkane $\mathrm{C}-\mathrm{H}$ bond (e.g., butane, propane)

2. $\mathrm{O}$ or $\mathrm{N}$ insertion into the surface reaction intermediate

3. $\mathrm{O}_{2}$ reduction to $\mathrm{O}^{2-}$ (lattice oxygen)

4. Lattice oxygen transfer (from the $\mathrm{O}_{2}$ reduction site to the $\mathrm{H}$-abstraction site)

5. Reoxidation (i.e., regeneration) of the $\mathrm{H}$-abstraction site

Experience has shown that although one metal constituent of a metal oxide is able to serve more than one of these functions, no single element has been shown to serve all the listed functions in a way that provides the highest reported yields and selectivity. That is, no single element oxide has been found that can catalyze the ammoxidation propylene in a single process step in the presence of propylene, ammonia, and oxygen (air) with high selectivity and yield. Thus, selective oxidation catalysts are typically mixed-metal oxides containing at least two metals $\left(\mathrm{Bi}_{2} \mathrm{Mo}_{3} \mathrm{O}_{12} ;(\mathrm{VO})_{2} \mathrm{P}_{2} \mathrm{O}_{7}\right)$, 
but usually three or more $\left(\mathrm{Bi}_{3} \mathrm{FeMo}_{2} \mathrm{O}_{12} ; \mathrm{Bi}_{1-x} \mathrm{Ce}_{x} \mathrm{Mo}_{12} ; \mathrm{K} / \mathrm{Ni} / \mathrm{Co} / \mathrm{Fe} / \mathrm{Bi} / \mathrm{Mo} / \mathrm{O}\right)$. It is not entirely surprising that among the bi- and tri-metallic oxides noted as having the requisite multifunctionality are single-phase materials. It has long been recognized in catalysis, whether with oxides (e.g., molecular compounds, solid solutions, zeolites) or with metals (bimetallic), that incorporating multiple elements within a single crystal structural framework affords an efficacious means for the seamless functioning of each element in the catalytic mechanism.

The more complex situation is the one in which multiple mixed-metal oxides are present and each appears to contribute in a beneficial way to either the activity or selectivity, or both, of a selective hydrocarbon oxidation reaction. The most industrially significant case in point is the selective oxidation and ammoxidation of propylene to acrolein and acrylonitrile, respectively $[12,13]$. This synergy between crystallographically distinct phases has been articulated in various ways in the literature. Although direct evidence for the proposed models is only now becoming available, a growing body of work is developing on the case of bi-phasic metallic catalysts [14]. Three models have been proposed for multiphasic metal-oxide catalysts to explain this synergistic process occurring between separate phases:

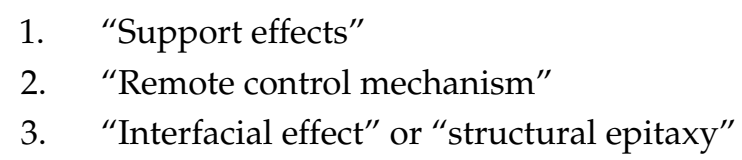

The "support effect" model envisions the catalytically active phase (in this case bismuth molybdate) supported on the second phase (cobalt molybdate or cobalt-iron molybdate), the later transporting its lattice oxygen to the bismuth molybdate phase under conditions of selective propylene oxidation to acrolein [15]. This model has also been described in terms of a core and shell configuration [16]. This model is generally an extension of the concept of supported metals spreading one phase (i.e., catalytically active metal) over a second phase (metal oxide support) via chemical wetting. This facilitates the physical interaction and thus the chemical and catalytic interactions of the two phases. This model has been applied to the mixed-metal oxide, bismuth-iron-cobalt-molybdate, selective-oxidation catalyst system, as mentioned above, where the promoting cobalt molybdate phase serves effectively as a support for the catalytically-active bismuth molybdate phase. The postulate of a "strong interaction" between the two phases serves as the conduit for the transfer of lattice oxygen during the catalytic cycle. However, this model offers no predictive or catalyst design utility as it can only truly offer an explanation for a catalyst that has already demonstrated multiple phase synergisms.

The "remote control" model also invokes the co-existence of two metal oxides in physical contact in a multiphase catalyst. With this model, one of the oxides serves as a so-called donor while the other is the so-called acceptor. The donor phase has the capability to dissociate $\mathrm{O}_{2}$ to create mobile surface-oxygen species that then migrate, or "spill over", to the acceptor phase (i.e., the phase with the active sites). The acceptor phase is generally the catalytically-active phase (bismuth molybdate in the case of propylene oxidation) with surface active sites for selective oxidation. This model has been applied to a wide range of multiphase metal oxides, including molybdenum, antimony and those based on vanadium oxide [17-19].

Finally, a more predictive model to describe the interactions between multiple phases in an oxide catalyst is one that invokes the well-known phenomenon of epitaxy. This model is grounded on well understood fundamental attributes of the chemistry of solid state materials. Epitaxy describes how two or more crystallographically distinct solid materials form chemically and structurally interacting phase boundaries (i.e., coherent interfaces). The application of this phenomenon to catalysis has been well described for a range of metal-oxide catalysts by Courtine and by Bordes [20-23]. It has proven to be among the most robust models, not only to explain existing multiphasic catalysts, but also as a foundation for a rational, practical and highly effective strategy for new catalyst design, especially for the design of the most complex catalyst systems that are used commercially in the petrochemical industry. This approach to catalyst function and design is the subject of the following section. 


\section{Chemical and Structural Multifunctionality}

\subsection{Multifunctionality within a Single-Phase, Metal-Oxide Catalyst}

\subsubsection{Bismuth Molybdate}

The quintessential example of a single-phase, heterogeneous, selective-oxidation catalyst is bismuth molybdate. It was a first-magnitude invention in partial oxidation catalyst development and it remains the prototype for most fundamental studies. This focus on bismuth molybdate is because it is well-recognized as the active phase of the molybdate-based allylic oxidation and ammoxidation catalysts used in industrial chemical processes for unsaturated aldehydes (acrolein from propylene), diolefins (butadiene from 1-butene) and nitriles (acrylonitrile from propylene). Bismuth molybdate exists in one of three known crystallographic phases: $\alpha-\mathrm{Bi}_{2} \mathrm{Mo}_{3} \mathrm{O}_{12}, \beta-\mathrm{Bi}_{2} \mathrm{Mo}_{2} \mathrm{O}_{9}$, and $\gamma-\mathrm{Bi}_{2} \mathrm{MoO}_{6}$. These structures have been characterized by $\mathrm{X}$-ray and neutron diffraction analyses [24-26]. Fundamental studies of the catalytic reaction kinetics and mechanisms, surface and bulk characterization and preparation chemistry for this commercially-consequential, binary, metal-oxide catalyst have been well described, reviewed and debated. The single phase $\alpha-\mathrm{Bi}_{2} \mathrm{Mo}_{3} \mathrm{O}_{12}$ served as the first commercial catalyst for the production of acrylonitrile by propylene ammoxidation. This paper will discuss the advances in catalyst design that have been built on this foundation.

\subsubsection{Bismuth-Iron Molybdate}

The incorporation of catalytically-functional, elemental components, such as a solid solution with a catalytically-active, scheelite bismuth molybdate phase was first demonstrated with iron and a single-phase, mixed-metal oxide with the formulation $\mathrm{Bi}_{3} \mathrm{FeMo}_{2} \mathrm{O}_{12}$ [27,28]. The incorporation of iron into this single-phase, mixed-metal oxide occurs by the substitution of Mo with Fe in the ideal scheelite $\mathrm{AMoO}_{4}$ structure that is driven by the size similarity of the ionic radii for $\mathrm{Fe}^{3+}$ and $\mathrm{Mo}^{6+}$ (64.5 pm and $59 \mathrm{pm}$, respectively [29]). Concomitantly, $\mathrm{Bi}^{3+}$ occupies the large A cation site of the scheelite structure. This single-phase, bismuth-iron-molybdate phase can exist in two distinct polymorphic forms. One form is disordered, with iron randomly distributed with molybdenum on the same crystallographic site in the tetragonal scheelite structure (the $X$ site in the top structure shown in Figure 1). The $\mathrm{Bi}^{3+}$ cation and any other large trivalent cation typified by $\mathrm{La}^{3+}$ occupy the $\mathrm{Y}$ site in the top structure shown in Figure 1. This polymorph has the high symmetry, tetragonal unit cell of the ideal $\mathrm{ABO}_{4}$ scheelite structure. The second polymorph is formed by the thermal treatment of the disordered phase at temperatures above about $500{ }^{\circ} \mathrm{C}$. It has iron and molybdenum ordered on the $\mathrm{X}$ sites, which yields a monoclinic structure type in the bottom structure view in Figure 1 (X1 is Mo and X2 is Fe in Figure 1). The resulting superstructure consists of three scheelite $\mathrm{ABO}_{4}$ subcells. For both the disordered and ordered phases the redox active element, iron, is atomically associated with bismuth molybdate in a single phase. The benefit of this is evident from the reported three-fold enhancement in the rate of oxidative dehydrogenation of 1-butene to butadiene when iron is present. Thus, the $\mathrm{Bi}_{3} \mathrm{FeMo}_{2} \mathrm{O}_{12}$ phase provides evidence that the close integration of a redox-active, multivalent element (i.e., $\mathrm{Fe}^{2+} \leftrightarrow \mathrm{Fe}^{3+}$ ) with a catalytically-active bismuth and molybdenum oxide active site can achieve significant enhancements in catalytic behavior in a selective oxidation reaction.

Subsequent to this earlier synthesis and structural characterization work, the presence of a disordered tetragonal $\mathrm{Bi}_{3} \mathrm{FeMo}_{2} \mathrm{O}_{12}$ phase was disclosed as providing significant yield improvements in a complex, mixed-metal-oxide catalyst for the selective oxidation and ammoxidation of an alcohol and/or alkene for the production of unsaturated nitriles, aldehydes or olefins, including the production of acrylonitrile by propylene ammoxidation [30]. The inventive feature is that the disordered single phase $\mathrm{Bi}_{3} \mathrm{FeMo}_{2} \mathrm{O}_{12}$ serves as the catalytically active phase of a multiphase mixture. This active phase, which contains iron in the $\mathrm{Fe}^{3+}$ oxidation state, co-exists with a second phase, $\mathrm{CoMoO}_{4}$. Under reaction conditions, a portion of the $\mathrm{Fe}^{3+}$ is likely reduced to the $\mathrm{Fe}^{2+}$ oxidation state (based on earlier catalyst characterization studies, in particular in references $[12,13])$ and coexists with $\mathrm{Co}^{2+}$ on the 
same crystallographic site in the cobalt molybdate structure. Additionally, the patent discloses that the disordered, active, scheelite phase has the more general formula $\mathrm{Bi}_{3-x} \mathrm{~A}_{\mathrm{x}} \mathrm{FeMo}_{2} \mathrm{O}_{12}$ where the $\mathrm{A}$ elements are present with $\mathrm{Bi}^{3+}$ on the same crystallographic site as described above. The A elements are large trivalent or divalent cations, including $\mathrm{La}^{3+}, \mathrm{Ce}^{3+}, \mathrm{Pr}^{3+}, \mathrm{Ca}^{2+}, \mathrm{Pb}^{2+}$.
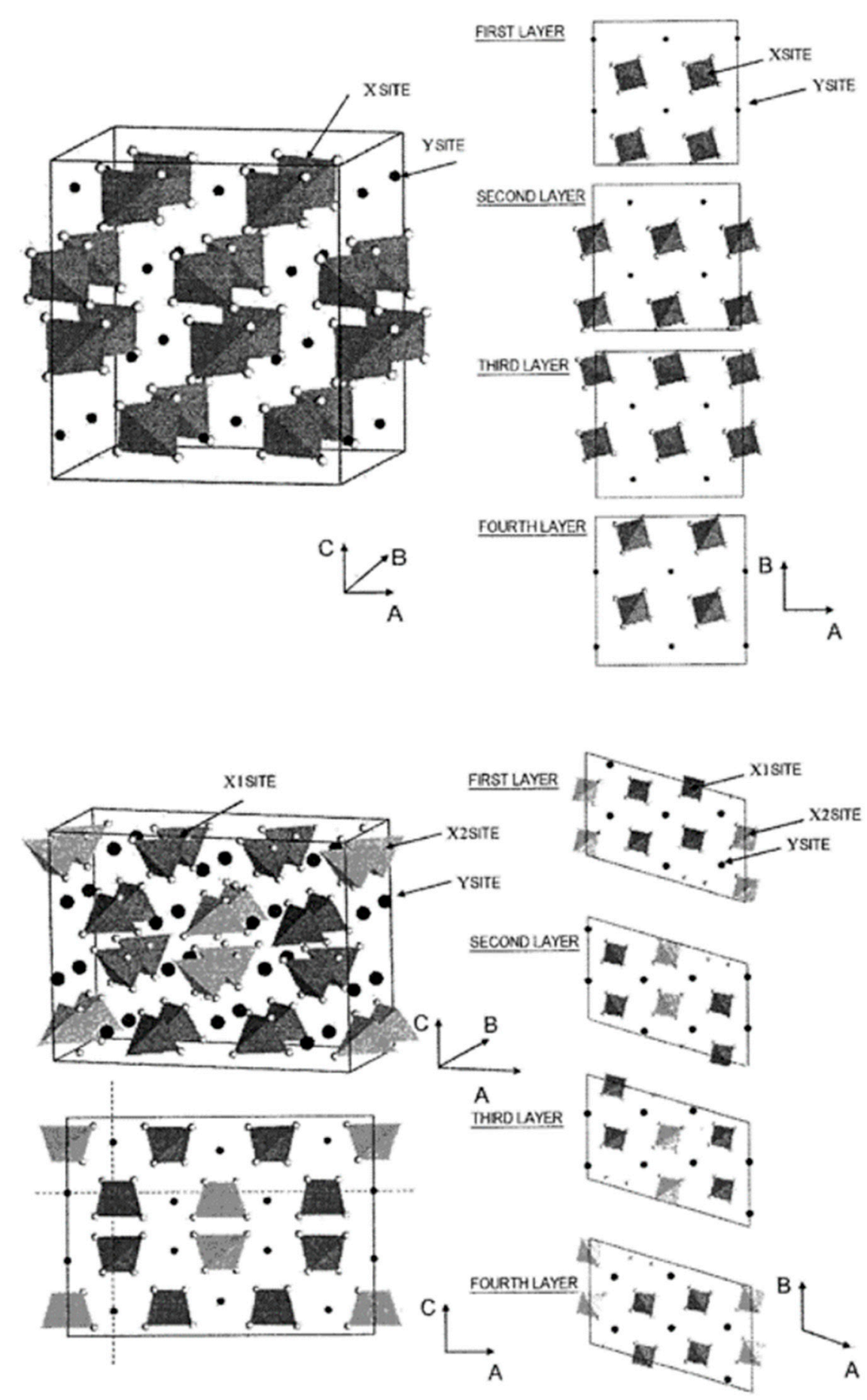

Figure 1. Schematic representation of the disordered (top) and ordered (bottom) $\mathrm{Bi}_{3} \mathrm{FeMo}_{2} \mathrm{O}_{12}$ phases. Source [30].

These complex catalysts are also always disclosed as including potassium, rubidium, or cesium in the formulation, but no information is provided on their specific function or crystal habit in the catalyst. Although they are large cations, they are not included among the A elements that can coexist in the 
disordered $\mathrm{Bi}_{3-x} \mathrm{~A}_{\mathrm{x}} \mathrm{FeMo}_{2} \mathrm{O}_{12}$ active phase. They are said to form crystallographic phases, presumably with molybdenum, that are separate and distinct from the disordered $\mathrm{Bi}_{3-x} \mathrm{~A}_{x} \mathrm{FeMo}_{2} \mathrm{O}_{12}$ active phase.

Also, particularly when designed for use in a fluid bed reactor, as is the case when producing acrylonitrile by propylene ammoxidation, the catalysts are shown to be prepared using various particle sizes ( $44 \mathrm{~nm}$ to $12 \mathrm{~nm}$ ) for $\mathrm{SiO}_{2}$ support for the catalytically-active molybdate phases described above. As described below, this is another manifestation of multifunctionality with an optimization involving a balance between:

a. Imparting the requisite physical strength to withstand the attritional environment of a fluid bed reactor; and

b. Achieving the highest selectivity to the desired partial oxidation product, acrylonitrile.

\subsubsection{Bismuth-Cerium Molybdate}

Another reported enhancement in single-phase bismuth-molybdate catalysts is bismuth-cerium molybdate solid solutions, which are reported to be highly effective catalysts for propylene ammoxidation [31-33]. Cerium has been disclosed in numerous patents as a required constituent of complex multicomponent catalysts for commercial applications [34-38]. The superior performance of these most recent commercial-type catalyst formulations can be understood from fundamental characterization studies of the bismuth-cerium-molybdate mixed-oxide system. The characterization studies revealed that the bismuth molybdate scheelite structure is able to accommodate a redox active element other than iron, namely cerium, but by a different mechanism compared to iron, as described above. By examining a broad composition range, covering the entire defect scheelite stoichiometry for the series $\mathrm{Bi}_{\mathrm{x}} \mathrm{Ce}_{2-\mathrm{x}} \mathrm{Mo}_{3} \mathrm{O}_{12}$ with $0 \leq \mathrm{x} \leq 2$, it was possible to construct a phase diagram for this mixed-metal-oxide system that revealed two solid solutions spanning this composition range. Based on structural characterization of the pure end member molybdate phases of the series [39], it was found that one solid solution consists of cerium dissolved in the $\alpha-\mathrm{Bi}_{2} \mathrm{Mo}_{3} \mathrm{O}_{12}$ structure for $\mathrm{x}$ greater than about 1.8 and a second solid solution consists of bismuth dissolved in the cerium molybdate structure when $x$ is less than about one. The enhanced catalytic activity and selectivity was concluded to result from the proximity of the $\mathrm{Ce}^{3+} \leftrightarrow \mathrm{Ce}^{4+}$ redox couple with the catalytically essential component bismuth and molybdenum responsible for the activation of propylene via $\alpha-\mathrm{H}$ abstraction and subsequent oxygen/nitrogen insertion. The role of a redox couple in selective oxidation catalysis has been shown, as discussed above, to facilitate lattice oxygen migration from the bulk to the surface active site.

In a similar way as described above for bismuth-iron molybdate, the solid-solution phase formed by bismuth dissolving in the cerium molybdate can exist within one of two structural polymorphs of the cerium molybdate phase-one with higher tetragonal unit cell symmetry [40] and the other with lower unit cell monoclinic symmetry [41]. When present as the bismuth-containing active molybdate phase in a complex mixed-metal-oxide catalyst for selective propylene ammoxidation, the monoclinic structure was shown to be preferred to achieve the best yields of acrylonitrile product $[42,43]$, as shown in Table 2.

Table 2. Propylene ammoxidation over bismuth-cerium molybdate containing complex mixed-metaloxide catalysts [42].

\begin{tabular}{ccc}
\hline $\begin{array}{c}\text { \% of Bismuth-Cerium Molybdate in } \\
\text { Monoclinic Scheelite Structure }\end{array}$ & $\begin{array}{c}\text { \% of Bismuth-Cerium Molybdate in } \\
\text { Tetragonal Scheelite Structure }\end{array}$ & $\begin{array}{c}\text { \% Acrylonitrile } \\
\text { Yield }\end{array}$ \\
\hline 38 & 62 & 79.8 \\
44 & 56 & 81.4 \\
48 & 52 & 82.5 \\
56 & 44 & 83.3 \\
59 & 41 & 84.2 \\
\hline
\end{tabular}

In the same way that iron in the bismuth-iron molybdate serves to enhance the functioning of this active phase within a complex mixed-metal-oxide catalyst, cerium analogously serves the 
role of redox promoter, but in this case its optimal catalytic performance occurs when it resides within the monoclinic defect scheelite structure of bismuth-cerium molybdate. The enhanced catalytic performance is thus a consequence of the atomic-level architecture with a single phase encompassing the three critical catalytic functions: propylene activation, nitrogen insertion and redox-promoted lattice oxygen transfer. The rationale for the beneficial effect is that within a solid solution the distance between the catalytically active elements (bismuth and molybdenum) and the multivalent redox active promoters (cerium and iron) is on the atomic scale. This situation produces the optimal conditions for interaction between element-specific functionalities in the catalyst. In support of this conjecture as a generally applicable design element of metal-oxide catalysts and selective oxidation catalysis, a single phase multi-metal-oxide, solid-solution model has now also been demonstrated to be the correct description for the operative solid state mechanism for the multifunctional MoVTeNbO catalyst for selective ammoxidation of propane to acrylonitrile [44]. The single so-called M1 phase incorporates the elements for all the necessary functions for the multistep chemical transformation of propane oxidative dehydrogenation to intermediate propylene $\left(\mathrm{V}^{5+}\right)$, propylene activation by $\alpha$-hydrogen abstraction to produce the allylic intermediate $\left(\mathrm{Te}^{4+}\right)$, oxygen and nitrogen insertion into the allylic intermediate to produce acrylonitrile $\left(\mathrm{Mo}^{6+}\right)$, and oxygen migration and redox activity $\left(\mathrm{V}^{5+} \leftrightarrow \mathrm{V}^{4+}\right)$.

The additional advantage of a solid-solution approach to designing the active phase of a catalyst is the opportunity to design new catalyst systems and for the continuous improvement of known active catalysts. In the case of the bismuth-cerium molybdate active phase, recent work has shown that the bismuth-cerium molybdate, solid-solution phase is not a simple homogeneous distribution of the bismuth and cerium cations in the defective scheelite structure [45]. Evidence points to a subtle preference of bismuth and cerium for specific crystallographic sites in the structure, which provides a unique distribution and a local environment of cations in the molybdate oxide structure. The addition of the multivalent rare earth cations samarium, praseodymium, and neodymium, which have a similar cation size to cerium, presents the prospect of enhancing redox functionality by the inclusion of these multivalent cations into a single solid solution of the active phase. Such catalyst formulations have achieved acrylonitrile yields from propylene of as high as $86 \%$ [46].

\subsection{Multifunctionality in a Multiphase Metal-Oxide Catalyst}

As described above, it is well recognized that lattice oxygen $\left(\mathrm{O}^{2-}\right)$ and electron migration are inherent critical functions within the Mars van-Krevelen mechanism for selective oxidation catalysts. How such a process occurs in the single-solid-state, oxide phase of a uniform structure is well understood [47], with cerium-containing oxides being notable examples of this phenomenon [48], as described above. However, the atomic level mechanism by which these transport phenomena occur in multiphasic oxide catalysts is less clear, especially when separate phases are assigned to disparate aspects of the process, e.g., $\mathrm{O}_{2}$ reduction to lattice $\mathrm{O}^{2-}$ versus lattice $\mathrm{O}^{2-}$ insertion into an allyl intermediate at the active site. One must invariably look to the chemistry and structure of the interfaces between such synergistically interacting phases to try and ascertain an operative mechanism. It is, therefore, worthwhile to examine the current solid-state chemistry understanding of the mechanism by which coexisting metal-oxide phases interact.

Many of the fundamental studies of the interaction of multiple phases in metal-oxide systems come from the materials science literature, particularly from studies of ceramics and electronic materials [49]. In general, there are three classifications for solid-solid interfaces, as shown in Figure 2:

- Coherent interfaces in which the lattice planes of the two phases in contact are continuous. This is typically described as an epitaxial interface and usually occurs through structurally-directed intergrowth at elevated synthesis temperatures.

- Incoherent interfaces where no lattice plane continuity exists across two phases.

- Semi-coherent interfaces in which a portion of the contacting lattice planes are continuous but are interspersed with regions of discontinuity. 

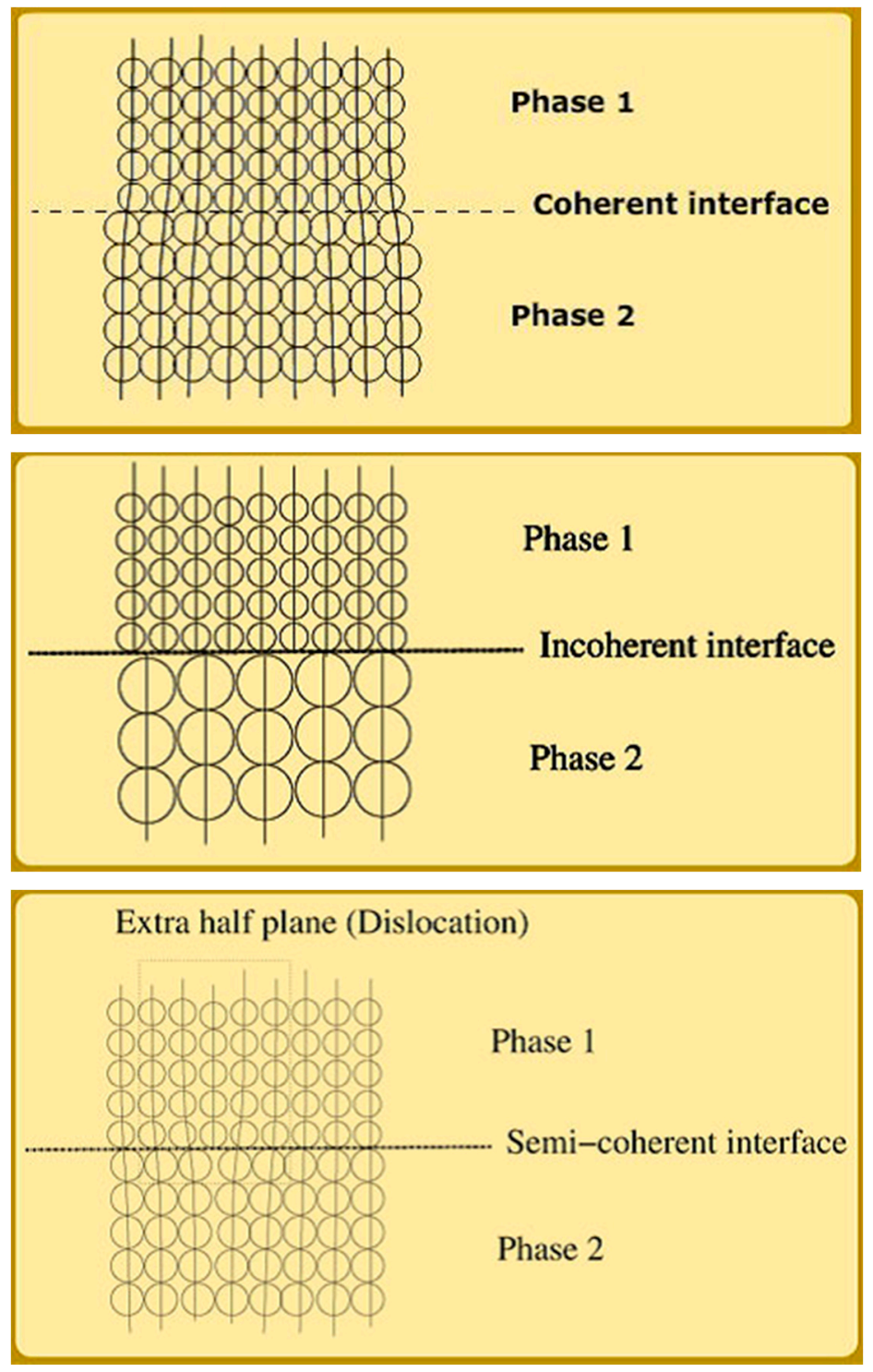

Figure 2. Schematic representations of possible interfacial structures for two contacting crystalline solids. Source: https:/ / nptel.ac.in/courses/113101003/downloads/partII/module1.pdf.

A method for assessing the likelihood of interfacial coherence is to calculate the lattice discontinuity, or disregistry $(\delta)$, for specific contacting crystal planes of two solids in which $d_{n}$ is the interplanar spacing for phase $n$.

$$
\delta=\left|\left(\mathrm{d}_{1}-\mathrm{d}_{2}\right)\right| / \mathrm{d}_{1}
$$

Generally, the values for $\delta$ for a coherent interface to exist are about $10 \%$ or less, while for a semi-coherent interface it is less than about $25 \%$, and for an incoherent interface it will be greater than about $25 \%$. The formation of coherent interfaces between two solids is driven by the minimization of the interfacial energy across the interface, which optimizes the boding across the two solids. Various ways have been described to identify and visualize the likelihood of coherent interface formation [50]. These methods helps reveal the likelihood of coherent interfacial interaction when applied to the few examples described in the catalyst literature for synergistic phase interaction for mixed-metal oxides, as shown in Table 3. 
Table 3. Examples of synergistic phase interactions in metal-oxide catalysts and possible epitaxial contact planes.

\begin{tabular}{|c|c|c|c|c|c|}
\hline Phase 1 & Phase 2 & Reference & $\begin{array}{c}\text { Possible Epitaxial } \\
\text { Contact Planes } \\
\text { Phase1/Phase2 }\end{array}$ & $\begin{array}{l}\text { Interplanar Spacing } \\
\mathrm{d}_{\text {Phase } 1} / \mathrm{d}_{\text {Phase } 2}(\mathrm{~nm})\end{array}$ & $\begin{array}{c}\text { Disregistry } \delta \\
(\%)\end{array}$ \\
\hline$\alpha-\mathrm{Bi}_{2} \mathrm{Mo}_{3} \mathrm{O}_{12}$ & $\beta-(\mathrm{Fe}, \mathrm{Co}) \mathrm{MoO}_{4}$ & {$[51,52]$} & $100 / 001$ & $7.68 / 7.07$ & 8 \\
\hline$(\mathrm{VO})_{2} \mathrm{P}_{2} \mathrm{O}_{7}$ & $\beta-\mathrm{CoMoO}_{4}$ & [53] & $100 / 110$ & $3.85 / 3.61$ & 6 \\
\hline $\mathrm{Bi}_{1.8} \mathrm{Ce}_{0.2} \mathrm{MoO}_{12}$ & $\mathrm{Bi}_{0.875} \mathrm{Ce}_{1.125} \mathrm{MoO}_{12}$ & [54] & 010/010 & $11.55 / 11.82$ & 2 \\
\hline
\end{tabular}

Conceptually, coherent and semi-coherent interfaces provide a local structure akin to a single phase, but with a compositional and structural gradient. Such a configuration would be expected to facilitate ionic, vacancy, and electronic transfer across the two phases, much as they would occur through a single solid phase. This transport phenomenon can be seen in solid-state fuel cell electrodes, for example [55,56].

In summary, the multifunctionality in a single phase and multiphase catalyst system can be represented by the schematic model shown in Figure 3.

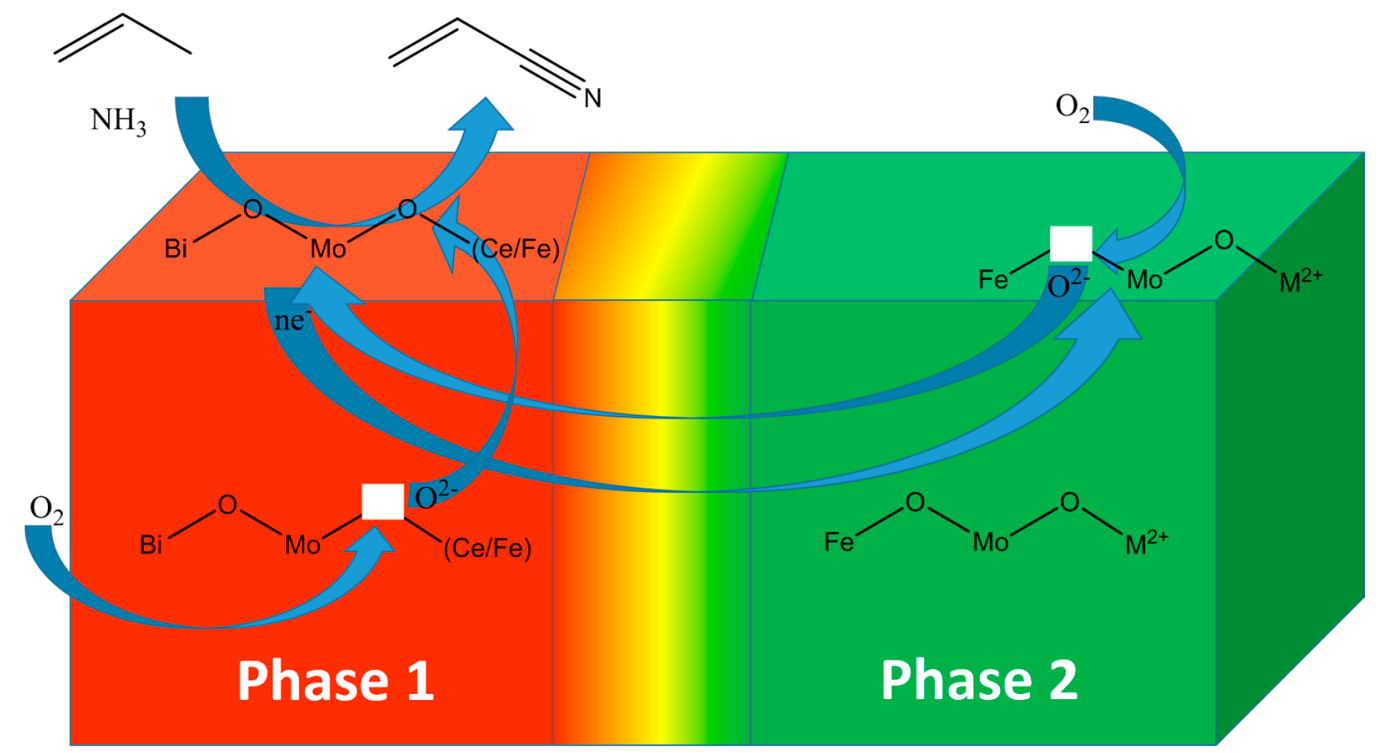

Figure 3. Schematic representation of multifunctionality in single and multiphase in an ammoxidation catalyst system.

The case where all the redox functionality resides in the same phase as the active site for propylene activation and transformation to acrylonitrile is represented by Phase 1 in the model. When the redox function of Phase 1 is promoted by a second phase, Phase 2, electron transfer and lattice oxygen migration is facilitated by the presence of a coherent interphase between the two phases. This coherency is the basis for the synergy in catalytic behavior that is observed when two or more phases coexist in a single mixed-metal-oxide catalyst system.

\section{Physical Multifunctionality}

Frequently overlooked and usually underappreciated, the physical properties of mixed-metal oxides are another important component of their multifunctional character and equally critical to their ability to function fully and effectively in the arduous environment of industrial operation. Although it is the chemical makeup of a mixed-metal-oxide catalyst that is necessary to engender its catalytic behavior, it is not sufficient when a commercial application is the goal. This is why the fundamental study of physical properties and their functional integration with the chemical 
properties of a complex oxide catalyst is not generally extensively studied in academic laboratories as are, for example, surface reaction kinetics and mechanisms, inorganic catalyst synthesis and solid state characterization. These critical physical properties for a typical commercial metal-oxide-catalyst system fall within the following general groupings, each of which can be viewed as a separate critical functionality of the catalyst:

1. Surface area, which encompasses both the available geometric and chemical areas

2. Porosity, including pore size, pore volume and pore structure

3. Strength, including crush, ablative and attrition resistance

4. Compositional integrity, which generally translate to a loss of catalyst components over time during operation

As with the individual chemical components and functionality of a mixed-metal oxide (see above), these physical functionalities are typically not independent of each other nor independent of the chemical makeup and properties of the catalyst. Instead, one property very often affects the quality of another. Thus, an understanding of the interplay between these properties, as well as their effect on catalyst performance, i.e., the surface reaction mechanism, is vital to the optimization of all these interacting functionalities in order to achieve the best overall performance in commercial operation. Suboptimal levels for any of these four physical parameters will translate into lower catalytic performance in terms of activity / conversion, desired product yield and selectivity, productivity and/or long-term stability /life of the catalyst. For example, low surface area will mean low activity, which is manifested in reduced reactant/feed conversion and catalyst productivity in terms of amount of desired product per amount of reactant or catalyst per unit time in hours, days or years. A pore size and pore structure that does not permit ready access of the reactant and product molecule to the active site will result in inefficient utilization of the catalytically active, and costly, elemental components. It will, as well, impart diffusion limitations into the kinetics of the reaction. The strength of the catalyst particle becomes a critical commercial operating parameter, as fine powders are not compatible with commercial-scale reactor types (i.e., generally fixed-bed and fluid-bed) nor practical to handle in the necessary multi-ton quantities used in chemical production plants. Thus, catalyst particles either must be shaped accordingly to about 0.3 to $2.5 \mathrm{~cm}$ diameter for fixed bed reactors, while fluid-bed reactors requires spherical particles in the range of 20-100 $\mu \mathrm{m}$ (microspheres). In the case of fixed-bed application, the particles have to possess sufficient crush strength to handle the stresses of being loaded into reactor tubes and to withstand the forces of pressure and flow variations during operation. In the case of fluid-bed reactor operation, the microspheroidal particles need a requisite level of attrition resistance so that they are not ablated and crushed to a powder during use, which causes poor hydrodynamic fluidization and the loss of fine catalyst particles from the reactor that need to be replaced at an economic cost. Finally, the relative contents of each of the elemental constituents must remain relatively constant over time during operation. The elemental composition is typically determined by long and costly experimentation and then set at the level that provides the highest overall yield and efficiency of the operation. Any change in the relative elemental composition due, for example, to preferential loss from the solid catalyst will, by definition, result in suboptimal operation, typically lower product yields. In summary, it is most important that attention be paid to all these physical and chemical parameters that work as a whole to define the overall observed catalytic behavior of a mixed-metal-oxide catalyst in commercial operation. Their optimal values are interdependent and their interplay typically means they cannot be set independently. Thus, these parameters in aggregate impact the ultimate performance of a solid catalyst in a complex but understandable way, as will be described below.

To begin to understand how to propitiously fine-tune the physical properties of a complex, mixed-metal-oxide, propylene-ammoxidation catalyst, it is important to recognize how such catalysts are typically prepared. Numerous variations of the preparation method have been described in the scientific and patent literature, with several variations notably providing one or more improvements 
in the performance of the catalyst [57]. The general method for manufacturing molybdate-based catalyst consists of combining an aqueous solution of ammonium molybdate with an aqueous solution containing the nitrate salts of the remaining elemental components, typically bismuth, iron, nickel, cobalt, magnesium, cerium among others, along with a colloidal silica sol. The combination results in precipitation of the metal salts to produce an aqueous slurry. The slurry is then dried, typically using a spray dryer, to generate microspheroidal particles for ultimate use in a fluid-bed reactor. Heat treatment of the dried particles is generally done at temperatures of up to 300 to $700{ }^{\circ} \mathrm{C}$ or at about $600{ }^{\circ} \mathrm{C}$. The use of a colloidal silica sol produces an amorphous silica during the subsequent heat treatment, which serves as the support that provides surface area, porosity and physical strength. The latter attribute is required for the catalyst to function successfully in the abrasive environment of a fluid-bed reactor. The properties of the silica sol will then generally largely define the critical physical characteristics of the final catalyst and thus also its catalytic performance [58].

To understand the role silica can serve in tailoring the physical properties of an ammoxidation catalyst, one needs to look at the patent literature, where the primary focus of the reported research results is on the preparation of catalysts for commercial scale operations. As a case in point, Figure 4 summarizes the data from a patent [59] describing the preparation and resulting physical properties of mixed-metal-oxide, propylene-ammoxidation catalysts containing bismuth and molybdenum that exquisitely illustrates the interrelation between the critical physical parameters of a metal oxide catalyst and catalyst performance. The data in Figure 4 show that the attrition resistance of a supported propylene ammoxidation improves (i.e., has less catalyst losses during operation in a commercial fluid-bed reactor) as the particle size of its silica support decreases-in this case from $86 \mathrm{~nm}$ to $8 \mathrm{~nm}$. In turn, though, the catalyst performance, as measured by yield of acrylonitrile from propylene, also decreases over this range. Further, the chart insert shows, as one would expect, that the amount of silica support also affects attrition resistance, with the higher level of silica support providing the harder, more attrition-resistant catalyst. However, the lower level of silica support provides a catalyst with a higher acrylonitrile product yield. Thus, the silica support affects two critical properties of an ammoxidation catalyst, namely attrition resistance and performance, but in conflicting ways. Successful catalyst design, thus, requires a balancing of the trade-off of two critical functionalities-attrition resistance and performance-in order to achieve the optimal operation of the catalyst. As this patent discloses, this fine-tuning can be accomplished by optimization around (1) the particle size of the colloidal silica used in the preparation, including the use of a mixture of different particle sizes as also disclosed in the patent data; and concurrently (2) the level of silica included in the catalyst formulation.

It is also worth noting the rare case where the catalyst formulation, by way of the choice of the elemental components and their relative levels, will have a direct impact on a physical property of the catalyst. It is normally understood that the elemental component is selected for catalyst formulation due to its function in directing the catalytic mechanism. Usually this is the overarching criterion for incorporating any element component. However, the situation can arise where the level of an essential component requires optimization, not only for activity and yield, but for a critical physical property such as attrition resistance. This is illustrated in Table S1 (Supplementary Materials) where modification in the elemental composition of an oxide directly impacts the attrition resistance of a complex, mixed-metal-oxide, ammoxidation catalyst [60].

Another critical functionality for a commercial catalyst is long-term stability, which means high operating yields over many thousands of hours of operation, including upsets in the operation resulting from unexpected deviations in reactor conditions and/or process parameters. Deficiencies in compositional integrity, another critical physical property of metal oxide catalysts, invariably result from the loss of one or more oxide components due to its volatility under the high temperature conditions and steam content in the vapor phase under selective oxidation reaction conditions. In the case of $\mathrm{Bi} / \mathrm{Mo} / \mathrm{O}-$ based catalysts, it is the loss of molybdenum oxide over time that degrades activity and product yields [61]. For $\mathrm{Fe} / \mathrm{Sb} / \mathrm{O}$ propylene ammoxidation catalysts containing tellurium as a promoter and the $\mathrm{Mo} / \mathrm{V} / \mathrm{Nb} / \mathrm{Te} / \mathrm{O}$ propane ammoxidation catalyst, tellurium oxide is lost during 
operation [62-64]. In the case of the latter, tellurium loss can also occur in the preparation process during heat treatment $[65,66]$. There is no especially effective way to prevent the loss of these volatile components. The best strategies have been to ameliorate the loss by replenishing the lost component from a separate source. For Bi/Mo/O-based catalysts, the loss of molybdenum occurs by the vapor transport of molybdenum hydroxide that forms during operation by the reaction of molybdenum oxide with steam at the $400{ }^{\circ} \mathrm{C}$ to $450{ }^{\circ} \mathrm{C}$ ammoxidation reaction temperature [67].

$$
\mathrm{MoO}_{3 \text { solid }}+\mathrm{H}_{2} \mathrm{O}_{\text {vapor }} \rightarrow \mathrm{MoO}_{2}(\mathrm{OH})_{2} \text { vapor }
$$

The volatile molybdenum is typically deposited on cool spots in the reactor thus contributing to the overall fouling of the equipment during operation. The loss of molybdenum results in declining activity and product yield over time which reduces the effective useful life of the catalyst. Methods disclosed to compensate for this loss of molybdenum from the catalyst include:

1. Ensuring an adequate or surplus level of molybdenum in the catalyst formulation such that the stoichiometry for the formation of molybdate compounds with the cationic elemental component of the catalyst is satisfied [68].

2. Adding to the reactor a supplementary catalyst containing an elevated level of molybdenum in its formulation [69].

3. Adding a molybdenum oxide source to the operating reactor on a regular basis $[70,71]$.

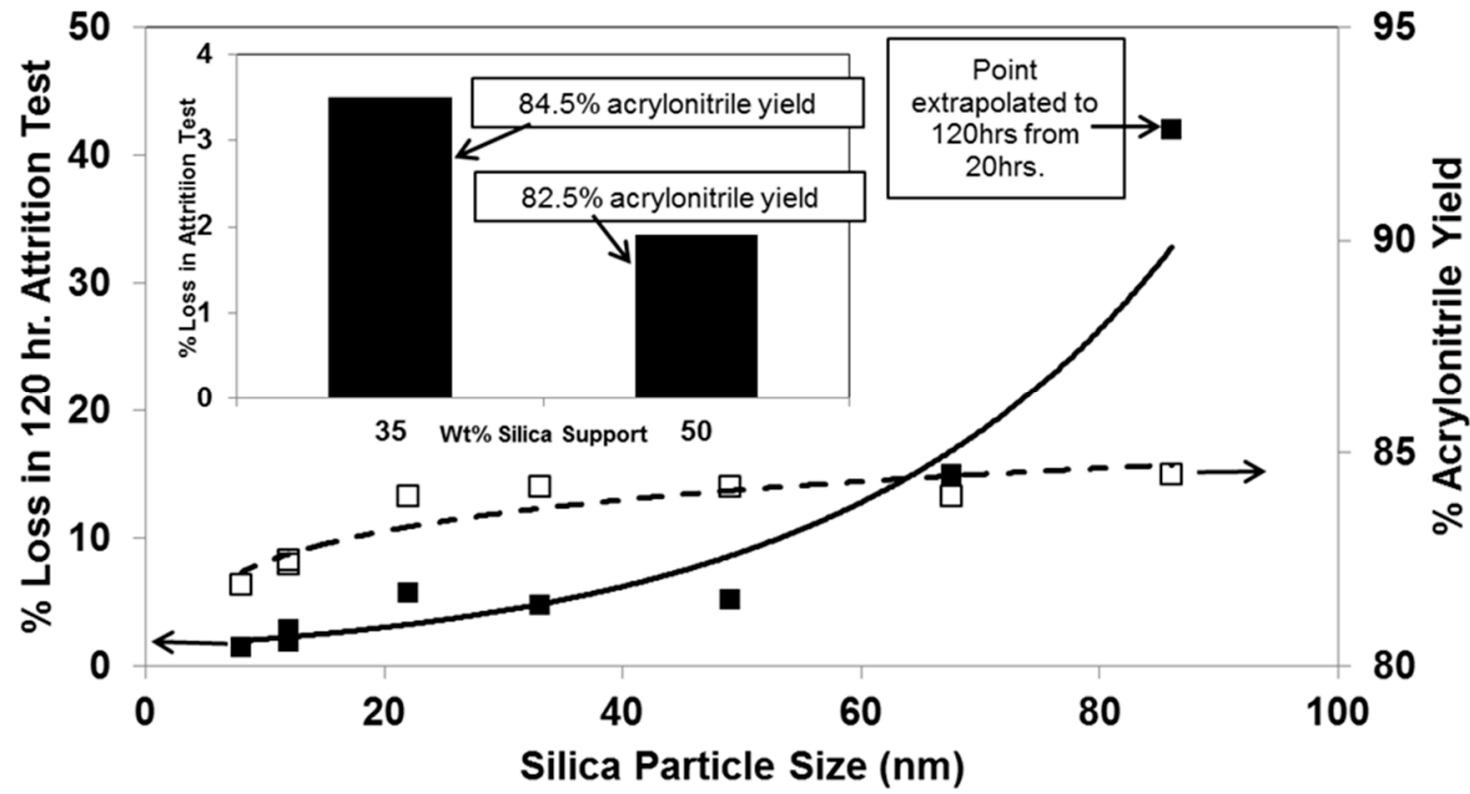

Figure 4. The effect of silica support particle size and amount on ammoxidation catalyst attrition resistance (hardness) and catalyst performance. See data source US Patent 7,473,666 for descriptions of attrition loss test and catalyst preparations. Insert shows data for identical catalyst composition supported on $12 \mathrm{~nm}$ silica at two support levels.

All these disclosed approaches rely on the ability of the added molybdenum source to be available to migrate to the operating catalyst and thereby maintain sufficient molybdenum content in the catalyst for optimal performance in terms of activity and product yield over an extended time of commercial operation.

For the tellurium-containing, mixed-metal oxides- $\mathrm{Fe} / \mathrm{Sb} / \mathrm{O}-$ based for propylene ammoxidation and $\mathrm{Mo} / \mathrm{V} / \mathrm{Nb} / \mathrm{Te} / \mathrm{O}$ for propane ammoxidation-similar approaches to those used for molybdenum replenishment have been described to ameliorate tellurium loss. Most notable is the method of adding a supplemental catalyst formulation during operation that has an elevated level of tellurium compared 
to the original catalyst $[72,73]$. The addition of the supplemental catalyst results in the transfer and redistribution of the tellurium between the two catalysts, thus replenishing what was lost during operation of the original catalyst over time.

Fundamentally, the most efficacious solution to element loss from a catalyst is to replace that element with one that is less or non-volatile and can serve the same function in the catalyst. In the case of tellurium in the $\mathrm{Mo} / \mathrm{V} / \mathrm{Nb} / \mathrm{Te} / \mathrm{O}$ propane ammoxidation catalyst, the replacement of tellurium by antimony is quite effective chemically, structurally and functionally [74]. It is so effective, in fact, that it is the approach taken commercially with the $\mathrm{Mo} / \mathrm{V} / \mathrm{Nb} / \mathrm{Sb} / \mathrm{O}$ catalyst formulation. This is the catalyst that has been scaled-up to commercial operation [75,76], rather tellurium analogue, which was discovered first and has been studied most in academic laboratories [77].

Thus, in summary, the physical properties of a mixed-metal-oxide, selective-ammoxidation catalyst, as is the case with any complex, multi-metal catalyst designed for commercial application, must be included in the pantheon of its multifunctional requirements. Understanding the mechanisms by which these physical characteristics of the catalyst are interwoven with its chemical properties is as important as uncovering the roles and interactions of the elemental constituents of the catalyst. It is only through rigorous optimization of all these textural variables that an industrially successful catalyst can be realized. The success of the catalyst design strategy described in this review can be exemplified by the most recent advances reported in the patent literature for the selective ammoxidation of propylene. Acrylonitrile yields from propylene in excess of $86 \%$, depending on the testing conditions, have been achieved. These acrylonitrile yields, which are among the highest reported, bespeak the superior effectiveness of these catalyst formulations, as well as the validity and practical utility of this catalyst design strategy (see Table 4). All three facets of the catalyst design strategy (or equivalently all three building blocks of catalyst design) are deployed and successfully integrated into a single functioning catalyst system—single phase chemical, multiphase chemical and physical functionalities.

Table 4. Examples of using the catalyst design strategies herein for incorporating chemical and physical multifunctionality for propylene ammoxidation to acrylonitrile.

\begin{tabular}{|c|c|c|c|c|c|c|c|c|c|}
\hline \multicolumn{7}{|c|}{ Catalyst Description } & \multirow{2}{*}{$\begin{array}{c}\begin{array}{c}\% \mathrm{C}_{3} \mathrm{H}_{6} \\
\text { Conv. }\end{array} \\
99.1\end{array}$} & \multirow{2}{*}{$\begin{array}{c}\begin{array}{c}\% \mathrm{C}_{3} \mathbf{H}_{3} \mathbf{N} \\
\text { Yield }\end{array} \\
76.3\end{array}$} & \multirow{2}{*}{$\begin{array}{l}\text { Ref. } \\
{[30]}\end{array}$} \\
\hline Cs & Co & $\mathrm{Fe}$ & $\mathrm{Bi}$ & & Mo Oxide & $\mathrm{SiO}_{2}$ (12 and $44 \mathrm{~nm}$ particle size) & & & \\
\hline Cs & Co & $\mathrm{Fe}$ & $\mathrm{Bi}$ & $\mathrm{Ce}$ & Mo Oxide & $\mathrm{SiO}_{2}$ (12 and $44 \mathrm{~nm}$ particle size) & 99.2 & 86.4 & [30] \\
\hline $\mathrm{Rb}$ & CoNiMg & $\mathrm{Fe}$ & $\mathrm{Bi}$ & $\mathrm{Ce}$ & Mo Oxide & $\mathrm{SiO}_{2}$ (12 and $44 \mathrm{~nm}$ particle size) & 99.3 & 86.0 & [30] \\
\hline Cs & Co & $\mathrm{Fe}$ & $\mathrm{Bi}$ & $\operatorname{Pr}$ & Mo Oxide & $\mathrm{SiO}_{2}$ (12 and $44 \mathrm{~nm}$ particle size) & 99.3 & 85.7 & [30] \\
\hline $\mathrm{Rb}$ & CoNiMg & $\mathrm{Fe}$ & $\mathrm{Bi}$ & $\mathrm{Ce}$ & Mo Oxide & $\mathrm{SiO}_{2}$ (12 and $41 \mathrm{~nm}$ particle size) & 99.2 & 85.1 & [78] \\
\hline $\mathrm{Rb}$ & $\mathrm{NiMg}$ & $\mathrm{FeCr}$ & $\mathrm{Bi}$ & $\mathrm{CeSm}$ & Mo Oxide & $\mathrm{SiO}_{2}(38.2 \mathrm{~nm}$ particle size $)$ & 98.8 & 85.8 & [46] \\
\hline
\end{tabular}

\section{Future Directions and Opportunities}

The propensity to and ubiquity of forming single-phase solid solutions and coherent interfaces between structurally different phases by no means explain all the known catalysts and catalytic phenomena surrounding selective-oxidation catalysis. These models are strictly highlighted in this review because they are among the most predictive, utilitarian and ultimately commercially successful models for the design of both new catalysts and catalysts with improved performance, mixed-metal-oxide-catalyst systems [79]. In the case of the selective oxidation and ammoxidation of propylene, the scheelite crystal structure has taken on the appearance of the quotidian vehicle for catalytic multifunctionality in both single phase and multiphase catalyst development, and fundamental studies in this specialized field [80]. Nevertheless, in principle, this fact does not exclude the possibility that other structural types can serve as a similar receptacle for multifunctionality for this and other selective oxidation and ammoxidation reactions of commercial interest.

In addition, there are very likely to be many more examples of catalysts that appear to be outliers of this model, but with closer examination would utilize features of these structural models in their working state. The continued focus and advances in the tools to characterize solids at the atomic level 
will be needed to uncover such evidence. These efforts will eventually reveal the fundamental nature and understanding of the structure, ionic transport mechanisms and complex elemental compositional distributions at the interface of interacting solids. Electron microscopy, especially aberration-corrected transmission electron microscopy (TEM) and high-angle annular dark-field scanning transmission electron microscopy (HAADF-STEM) has led the way on this scientific journey of atomic-level visualization of complex solid mixtures, including catalysts of various kinds. In addition, resonant, high-energy X-ray diffraction [81] has recently proven itself to be an extremely useful new technique for uncovering solid-solution formations in bimetallic catalyst systems that appear to be immiscible but actually do form true solid solutions that occur at the nano-scale [82]. Application of this developing tool to mixed-metal-oxide catalysts may uncover the same phenomenon in known selective-oxidation catalysts. This will be critically important information to obtain under high temperature and reaction conditions of typical working commercial catalyst systems, where significant atomic level restructuring likely occurs. It is also worth noting that many instances continue to come to light where the core principles of these models have been shown to be operative for apparently disparate catalytic processes and catalysts $[83,84]$.

Multifunctionality will continue to be of increasing importance in the design of future generations of catalysts both for existing and for new chemical processes. This will be driven by the need for ever-increasing selectivity, due to the competitive existential commercial requirement to increase process efficiency and thus significantly reduce the cost of manufacture, including reducing capital cost requirements for new production capacities. Well-designed and coordinated multifunctionality will also be the only effective catalyst design strategy to effect selective conversions of lower cost and readily available chemical substrates, including alkanes, biomass and even $\mathrm{CO}_{2}$. For example, catalytic processes have even been proposed for producing acrylonitrile, acrolein and acrylic acid from the biomass-derived feedstocks glycerol [85,86], propylene glycol [87] and 3-hydroxypropionic acid [88]. However, these ostensibly nascent technologies will face significant hurdles to commercial-scale application that are not only technological, but also economic, societal and ethical [89]. The commercial viability of processes based on such bio-derived reagents will depend on their availability and price which, to date, are driven overwhelmingly by government mandates for biochemicals and biofuels, notably biodiesel, rather than by market supply and demand. Nevertheless, any of these potential future chemical feedstocks are inherently difficult to activate and then selectively convert to products that are invariably more reactive than the molecules from which they are derived. A simple example of this is the oxidative dehydrogenation of alkanes to produce the corresponding alkenes. Therein resides the quintessential challenge for a viable industrial catalytic process including selective oxidation and ammoxidation.

Supplementary Materials: The following are available online at www.mdpi.com/2073-4344/8/3/103/s1, Table S1: Attrition resistance as a function of catalyst composition for a silica supported $\mathrm{Ni} / \mathrm{Mg} / \mathrm{Fe} / \mathrm{Rb} / \mathrm{Cr} / \mathrm{Bi}$ / $\mathrm{Ce} / \mathrm{Mo} /$ Oxide propylene ammoxidation catalyst1.

Conflicts of Interest: The author declares no conflict of interest.

\section{References}

1. Grasselli, R.K. Fundamental principles of selective heterogeneous oxidation catalysis. Top. Catal. 2002, 21, 79-88. [CrossRef]

2. Védrine, J.C. Heterogeneous artial (amm)oxidation and oxidative dehydrogenation catalysis on mixed metal oxides. Catalysts 2016, 6, 22. [CrossRef]

3. Védrine, J.C.; Fechete, I. Heterogeneous partial oxidation catalysis on metal oxides. C. R. Chim. 2016, 19, 1203-1225. [CrossRef]

4. Brazdil, J.F. Selective oxidation in industry: Applications of metal oxides in the petrochemical industry. In Metal Oxides in Heterogeneous Catalysis; Védrine, J.C., Ed.; Elsevier: Amsterdam, The Netherlands, 2018; pp. 455-502, ISBN 9780128116326. 
5. Grasselli, R.K. Site isolation and phase cooperation: Two important concepts in selective oxidation catalysis: A retrospective. Catal. Today 2014, 238, 10-27. [CrossRef]

6. Schlögl, R. Selective oxidation: From a still immature technology to the roots of catalysis science. Top. Catal. 2016, 59, 1461-1476. [CrossRef]

7. Callahan, J.L.; Grasselli, R.K. A selectivity factor in vapor-phase hydrocarbon oxidation catalysis. AIChE J. 1963, 9, 755-760. [CrossRef]

8. Callahan, J.L.; Grasselli, R.K.; Milberger, E.C.; Strecker, H.A. Oxidation and ammoxidation of propylene over bismuth molybdate catalyst. Ind. Eng. Chem. Prod. Res. Dev. 1970, 9, 134-142. [CrossRef]

9. Brazdil, J.F.; Toft, M.A. Ammoxidation. In Encyclopedia of Catalysis; Horváth, I.T., Ed.; John Wiley \& Sons, Inc.: Hoboken, NJ, USA, 2010; ISBN 9780471227618.

10. Burrington, J.D.; Kartisek, C.T.; Grasselli, R.K. Surface intermediates in selective propylene oxidation and ammoxidation over heterogeneous molybdate and antimonate catalysts. J. Catal. 1984, 87, 363-380. [CrossRef]

11. Licht, R.B.; Vogt, D.; Bell, A.T. The mechanism and kinetics of propene ammoxidation over a-bismuth molybdate. J. Catal. 2016, 339, 228-241. [CrossRef]

12. Ponceblanc, H.; Millet, J.M.M.; Coudurier, G.; Herrmann, J.M.; Védrine, J.C. Study of multiphasic molybdate-based catalysts: I. Electrical conductivity study of valence states and solubility limits in mixed iron and cobalt molybdates. J. Catal. 1993, 142, 373-380. [CrossRef]

13. Millet, J.M.M.; Ponceblanc, H.; Coudurier, G.; Herrmann, J.M.; Védrine, J.C. Study of multiphasic molybdate-based catalysts: II. Synergy effect between bismuth molybdates and mixed iron and cobalt molybdates in mild oxidation of propene. J. Catal. 1993, 142, 381-391. [CrossRef]

14. Petkov, V.; Wanjala, B.N.; Loukrakpam, R.; Luo, J.; Yang, L.; Zhong, C.; Shastri, S. Pt-Au alloying at the nanoscale. Nano Lett. 2012, 12, 4289-4299. [CrossRef] [PubMed]

15. Moro-oka, Y.; He, D.-H.; Ueda, W. Studies in Surface Science and Catalysis; Grasselli, R.K., Sleight, A.W., Eds.; Elsevier Science: Amsterdam, The Netherlands, 1991; Volume 67, pp. 57-66. ISBN 978-0-444-88942-3.

16. Wolfs, M.W.J.; Batist, P.H.A. The selective oxidation of 1-butene over a multicomponent molybdate catalyst. Influences of various elements on structure and activity. J. Catal. 1974, 32, 25-36. [CrossRef]

17. Weng, L.T.; Sham, E.; Doumain, B.; Ruiz, P.; Delmon, B. Studies in Surface Science and Catalysis; Centi, G., Trifiro, F., Eds.; Elsevier Science: Amsterdam, The Netherlands, 1990; Volume 55, pp. 757-765, ISBN 9780080879185.

18. Weng, L.T.; Patrono, P.; Sham, E.; Ruiz, P.; Delmon, B. Studies in Surface Science and Catalysis; Centi, G., Trifiro, F., Eds.; Elsevier Science: Amsterdam, The Netherlands, 1990; Volume 55, pp. 797-806, ISBN 9780080879185.

19. Cadus, L.E.; Xiong, Y.L.; Gotor, F.J.; Acosta, D.; Naud, J.; Ruiz, P.; Delmon, B. Studies in Surface Science and Catalysis; Centi, G., Trifiro, F., Eds.; Elsevier Science: Amsterdam, The Netherlands, 1990; Volume 82, pp. 41-54, ISBN 9780080879901.

20. Véjux, A.; Courtine, $\mathrm{P}$. Interfacial reactions between $\mathrm{V}_{2} \mathrm{O}_{5}$ and $\mathrm{TiO}_{2}$ (anatase): Role of the structural properties. J. Solid State Chem. 1978, 23, 93-103. [CrossRef]

21. Courtine, P. Thermodynamic and structural aspects of interfacial effects in mild oxidation catalysts. In Solid State Chemistry in Catalysis; Grasselli, R.K., Brazdil, J.F., Eds.; ACS Symposium Series; American Chemical Society: Washington, DC, USA, 1985; Volume 279, pp. 57-74, ISBN 9780841211100.

22. Courtine, P.; Bordes, E. Studies in Surface Science and Catalysis; Grasselli, R.K., Oyama, S.T., Gaffney, A.M., Lyons, J.E., Eds.; Elsevier Science: Amsterdam, The Netherlands, 1997; Volume 110, pp. 177-184, ISBN 9780080544717.

23. Bordes, E. Synergistic effects in selective oxidation catalysis: Does phase cooperation result in site isolation? Top. Catal. 2001, 15, 131-137. [CrossRef]

24. Aykan, K. Reduction of $\mathrm{Bi}_{2} \mathrm{O}_{3} \mathrm{MoO}_{3}$ catalyst during the ammoxidation of propylene in the absence of gaseous oxygen. J. Catal. 1968, 12, 281-290. [CrossRef]

25. Van den Elzen, A.F.; Riech, G.D. An outline of the crystal-structure of $\mathrm{Bi}_{2} \mathrm{Mo}_{2} \mathrm{O}_{9}$. Mater. Res. Bull. 1975, 10, 1163-1168. [CrossRef]

26. Teller, R.G.; Brazdil, J.F.; Grasselli, R.K.; Jorgensen, J.D. The structure of $\gamma$-bismuth molybdate, $\mathrm{Bi}_{2} \mathrm{MoO}_{6}$, by powder neutron diffraction. Acta Crystallogr. Sect. C 1984, 40, 2001-2005. [CrossRef] 
27. Sleight, A.W.; Jeitschko, W. $\mathrm{Bi}_{3}\left(\mathrm{FeO}_{4}\right)\left(\mathrm{MoO}_{4}\right)_{2}$ and $\mathrm{Bi}_{3}\left(\mathrm{GaO}_{4}\right)\left(\mathrm{MoO}_{4}\right)_{2}-\mathrm{New}$ compounds with scheelite related structures. Mater. Res. Bull. 1974, 9, 951-954. [CrossRef]

28. Jeitschko, W.; Sleight, A.W.; McClellan, W.R.; Weiher, J.F. A comprehensive study of disordered and ordered scheelite-related $\mathrm{Bi}_{3}\left(\mathrm{FeO}_{4}\right)\left(\mathrm{MoO}_{4}\right)_{2}$. Acta Crystallogr. Sect. B 1976, 32, 1163-1170. [CrossRef]

29. Shannon, R.D. Revised effective ionic radii and systematic studies of interatomic distances in halides and chalcogenides. Acta Crystallogr. 1976, A32, 751-767. [CrossRef]

30. Yoshida, J.; Yamaguchi, T. Oxide Catalyst and Method for Producing the Same, and Methods for Producing Unsaturated Aldehyde, Diolefin, and Unsaturated Nitrile. U.S. Patent 9,364,817, 14 June 2016.

31. Brazdil, J.F.; Grasselli, R.K. Relationship between solid state structure and catalytic activity of rare earth and bismuth-containing molybdate ammoxidation catalysts. J. Catal. 1983, 79, 104-117. [CrossRef]

32. Giordano, N.; Bart, J.C.J. On the mechanism of ammoxidation of propene over cerium-doped bismuth molybdate catalysts. Recl. Trav. Chim. Pays-Bas 1975, 94, 28-30. [CrossRef]

33. Brazdil, J.F.; Glaeser, L.C.; Grasselli, R.K. Role of interfacial phenomena in the catalytic behavior of multiphase selective ammoxidation catalysts. J. Phys. Chem. 1983, 87, 5485-5491. [CrossRef]

34. Suresh, D.D.; Friedrich, M.S.; Seely, M.J. Catalyst for Process for Manufacture of Acrylonitrile and Methacrylonitrile. U.S. Patent 5,093,299, 3 March 1992.

35. Suresh, D.D.; Friedrich, M.S.; Seely, M.J. Catalyst for the Manufacture of Acrylonitrile and Methacrylonitrile. U.S. Patent 5,212,137, 18 May 1993.

36. Midorikawa, H.; Someya, K.; Aoki, K.; Nagano, O. Ammoxidation Catalyst Composition and Process for Producing Acrylonitrile or Methacrylonitrile Using the Same. U.S. Patent 5,658,842, 19 August 1997.

37. Paparizos, C.; Jevne, S.C.; Seely, M.J. Catalyst for the Manufacture of Acrylonitrile. U.S. Patent 7,071,140, 4 July 2006.

38. Paparizos, C.; Jevne, S.C.; Seely, M.J. Catalyst for the Manufacture of Acrylonitrile. U.S. Patent 7,348,291, 25 March 2008.

39. Jeitschko, W. Crystal structure of $\mathrm{La}_{2}\left(\mathrm{MoO}_{4}\right)_{3}$, a new ordered defect Scheelite type. Acta Crystallogr. 1973, B29, 2074-2081. [CrossRef]

40. Huang, Q.; Xu, J.; Li, W. Preparation of tetragonal defect scheelite-type $\mathrm{RE}_{2}\left(\mathrm{MoO}_{4}\right)_{3}(\mathrm{RE}=\mathrm{La}$ to Ho$)$ by precipitation method. Solid State Ionics 1989, 32/33, 244-249. [CrossRef]

41. Brixner, L.H.; Sleight, A.W.; Licis, M.S. Cell Dimensions of the Molybdates $\mathrm{La}_{2}\left(\mathrm{MoO}_{4}\right)_{3} \mathrm{Ce}_{2}\left(\mathrm{MoO}_{4}\right)_{3}$, $\mathrm{Pr}_{2}\left(\mathrm{MoO}_{4}\right)_{3}$ and $\mathrm{Nd}_{2}\left(\mathrm{MoO}_{4}\right)_{3}$. J. Solid State Chem. 1972, 5, 247-249. [CrossRef]

42. Brazdil, J.F.; Toft, M.A.; McKenna, S.T. Mixed Metal Oxide Catalysts. U.S. Patent 9,433,929, 6 September 2016.

43. Brazdil, J.F.; Toft, M.A.; McKenna, S.T. Mixed Metal Oxide Catalysts. U.S. Patent 9,550,729, 24 January 2017.

44. Woo, J.; Sanghavi, U.; Vonderheide, A.; Guliants, V. A study of M1/M2 phase synergy in the MoVTe(Nb,Ta)O catalysts for propane ammoxidation to acrylonitrile. Appl. Catal. A Gen. 2016, 515, 179-189. [CrossRef]

45. Brazdil, J.F.; Toft, M.A.; Lin, S.Y.; McKenna, S.T.; Zajac, G.; Kaduk, J.A.; Golab, J.T. Characterization of bismuth-cerium-molybdate selective propylene ammoxidation catalysts. Appl. Catal. A Gen. 2015, 495, 115-123. [CrossRef]

46. Brazdil, J.F.; Lin, S.Y. Ammoxidation Catalysts Containing Samarium. U.S. Patent 2017/0114007, 27 April 2017.

47. Lankhorst, M.H.R.; Bouwmeester, H.J.M.; Verweij, H. Thermodynamics and transport of ionic and electronic defects in crystalline oxides. J. Am. Ceram. Soc. 1997, 80, 2175-2198. [CrossRef]

48. Chen, D.; He, D.; Lu, J.; Zhong, L.; Liu, F.; Liu, J.; Yu, J.; Wan, G.; He, S.; Luo, Y. Investigation of the role of surface lattice oxygen and bulk lattice oxygen migration of cerium-based oxygen carriers: XPS and designedH2-TPR characterization. Appl. Catal. B Environ. 2017, 218, 249-259. [CrossRef]

49. Van Der Merwe, J.H. The role of lattice misfit in epitaxy. Crit. Rev. Solid State Mater. Sci. 1978, 7, $209-231$. [CrossRef]

50. De Schutter, B.; De Keyser, K.; Detavernier, C. Visualization and classification of epitaxial alignment at hetero-phase boundaries. Solid Films 2016, 599, 104-112. [CrossRef]

51. Ponceblanc, H.; Millet, J.M.M.; Coudurier, G.; Legendre, O.; Védrine, J.C. Solid-solid phase equilibria in the binary system $\mathrm{CoMoO}_{4}-\mathrm{FeMoO}_{4}$ and effect of $\mathrm{Fe}$ III on the phase equilibria. J. Phys. Chem. 1992, 96, 9462-9465. [CrossRef] 
52. Brazdil, J.F.; Mehici, M.; Glaeser, L.C.; Hazle, M.A.S.; Grasselli, R.K. Correlation between spectroscopic measurements and catalytic behavior of selective oxidation catalysts. In Catalyst Characterization Science; Deviney, M.L., Gland, J.L., Eds.; ACS Symposium Series; American Chemical Society: Washington, DC, USA, 1985; Volume 288, pp. 26-36, ISBN 9780841211209.

53. Bordes, E. Comparative study of structure-sensitive oxidation of n-butane and 1-butene in maleic anhydride on two kinds of catalysts. In Studies in Surface Science and Catalysis; Centi, G., Trifiro, F., Eds.; Elsevier Science: Amsterdam, The Netherlands, 1990; Volume 55, pp. 585-592, ISBN 9780080879185.

54. Brazdil, J.F. A critical perspective on the design and development of metal oxide catalysts for selective propylene ammoxidation and oxidation. Appl. Catal. A Gen. 2017, 543, 225-233. [CrossRef]

55. Volkov, S.; Vonk, V.; Khorshidi, N.; Franz, D.; Kubicek, M.; Kilic, V.; Felici, R.; Huber, T.M.; Navickas, E.; Rupp, G.M.; et al. Operando X-ray Investigation of Electrode/Electrolyte Interfaces in Model Solid Oxide Fuel Cells. Chem. Mater. 2016, 28, 3727-3733. [CrossRef] [PubMed]

56. Gilardi, E.; Gregori, G.; Wang, Y.; Sigle, W.; van Aken, P.A.; Maier, J. Interface Effects on the Ion Transport of Epitaxial $\mathrm{Y}_{2} \mathrm{Zr}_{2} \mathrm{O}_{7}$ Films. ACS Appl. Mater. Interfaces 2017, 9, 27257-27265. [CrossRef] [PubMed]

57. Besecker, C.J.; Brazdil, J.F.; Toft, M.A.; Seely, M.J.; Gustaferro, R.A. Process for Preparing Improved Mixed Metal Oxide Ammoxidation Catalysts. U.S. Patent 8,258,073, 4 September 2012.

58. Lugmair, C.G. Metal Oxide Catalyst Material and Process for Making and Using Same. U.S. Patent 9,815,045, 14 November 2017.

59. Yanagi, H.; Midorikawa, H.; Ueda, T. Particulate Porous Ammoxidation Catalyst. U.S. Patent 7,473,666, 6 January 2009.

60. Brazdil, J.F.; Toft, M.A.; Seely, M.J.; Besescker, C.J.; Gustaferro, R.A. Attrition Resistant Mixed Metal Oxide Ammoxidation Catalysts. U.S. Patent 8,455,388, 4 June 2013.

61. Callahan, J.L.; Shaw, W.G.; Miller, A.F. Reactivation of Molybdenum Containing Oxidation Catalysts in Fluid Bed Reactors. U.S. Patent 3,882,159, 6 May 1975.

62. Sasaki, Y.; Kiyomiya, Y.; Nakamura, T. Process for Improving the Activity of Tellurium Containing Metal Oxide Catalysts. U.S. Patent 4,709,071, 24 November 1987.

63. Valente, J.S.; Armendáriz-Herrera, H.; Quintana-Solórzano, R.; del Ángel, P.; Nava, N.; Massó, A.; López Nieto, J.M. Chemical, structural, and morphological changes of a MoVTeNb catalyst during oxidative dehydrogenation of ethane. ACS Catal. 2014, 4, 1292-1301. [CrossRef]

64. Lwin, S.; Diao, W.; Baroi, C.; Gaffney, A.M.; Fushimi, R.R. Characterization of $\mathrm{MoVTeNbO}_{\mathrm{x}}$ catalysts during oxidation reactions using in situ/operando techniques: A review. Catalysts 2017, 7, 109. [CrossRef]

65. Popova, G.Y.; Andrushkevich, T.V.; Chesalov, Y.A.; Plyasova, L.M.; Dovlitova, L.S.; Ischenko, E.V.; Aleshina, G.I.; Khramov, M.I. Formation of active phases in MoVTeNb oxide catalysts for ammoxidation of propane. Catal. Today 2009, 144, 312-317. [CrossRef]

66. Popova, G.Y.; Andrushkevich, T.V.; Dovlitova, L.S.; Aleshina, G.A.; Chesalov, Y.A.; Ishenko, A.V.; Ishenko, E.V.; Plyasova, L.M.; Malakhov, V.V.; Khramov, M.I. The investigation of chemical and phase composition of solid precursor of $\mathrm{MoVTeNb}$ oxide catalyst and its transformation during the thermal treatment. Appl. Catal. A Gen. 2009, 353, 249-257. [CrossRef]

67. Kameo, H.; Kajitani, H.; Iwakai, K.; Takeo, H.; Orita, S.; Takeuchi, T. Method for Producing Conjugated Diene. U.S. Patent 9,340,472, 17 May 2016.

68. Watanabe, H.; Yanagita, M.; Miyaki, K. Catalyst for Producing Acrylonitrile and Process for Producing Acrylonitrile. U.S. Patent 8,034,737, 11 October 2011.

69. Chen, X.; Wu, L. Supplementary Catalyst for Ammoxidation Catalysts. U.S. Patent 5,177,048, 5 January 1993.

70. Elischer, S.; Lienhard, K.; Tautz, H. Process for Reactivating Molybdenum-Containing Catalysts. DE 3,311,521 A1, 18 August 1984.

71. Watanabe, H.; Yanagita, M.; Karasuda, T.; Nishida, K.; Miyaki, K. Method for Producing Acrylonitrile. U.S. Patent 9,334,233, 1 May 2016.

72. Watanabe, H.; Yanagita, M.; Karasuda, T.; Nishida, K.; Miyaki, K. Method for Producing Acrylonitrile. U.S. Patent 9,181,178, 10 November 2015.

73. Karasuda, T.; Watanabe, H.; Yanagita, M.; Nishida, K. Method for Producing Acrylonitrile. U.S. Patent 9,328,063, 3 May 2016.

74. Deniau, B.; Nguyen, T.T.; Delichere, P.; Safonova, O.; Millet, J.M. Redox state dynamics at the surface of $\mathrm{MoVTe}(\mathrm{Sb}) \mathrm{NbO} \mathrm{M} 1$ phase in selective oxidation of light alkanes. Top. Catal. 2013, 56, 1952-1962. [CrossRef] 
75. Yushuke, I.; Kazushi, O. Oxide Catalyst, Production Method Therefor, and Unsaturated Nitrile Production Method. WO2015133510A1, 4 March 2015.

76. Tateno, E.; Ichihara, T.; Kato, T. Oxide Catalyst, Process for Producing Oxide Catalyst, Process for Producing Unsaturated Acid and Process for Producing Unsaturated Nitrile. U.S. Patent 9,427,727, 30 August 2016.

77. Ushikubo, T.; Sawaki, I.; Oshima, K.; Inumaru, K.; Kobayakawa, S.; Kiyono, K. Process for Preparing a Catalyst Useful for Producing a Nitrile. U.S. Patent 5,422,328, 6 June 1995.

78. Akiyoshi, F.; Masatoshi, K. Fluid bed Ammoxidation Reaction Catalyst, and Acrylonitrile Production Method. WO2017130909A1, 3 August 2017.

79. Brazdil, J.F. Selective oxidation in industry: Applications of metal oxides in the petrochemical industry, Chapter 8-2. In Heterogeneous Catalysis by Metal Oxides; Védrine, J.C., Ed.; Elsevier: Amsterdam, The Netherlands, 2017.

80. Brazdil, J.F. Scheelite: A versatile structural template for selective alkene oxidation catalysts. Catal. Sci. Technol. 2015, 5, 3452-3458. [CrossRef]

81. Joly, Y.; Matteo, S.D.; Bunău, O. Resonant X-ray diffraction: Basic theoretical principles. Eur. Phys. J. Spec. Top. 2012, 208, 21-38. [CrossRef]

82. Bond, G.E. The electronic structure of platinum-gold alloy particles. Platinum Metals Rev. 2007, 51, 63-68. [CrossRef]

83. Wang, J.; Li, G.; Li, Z.; Tang, C.; Feng, Z.; An, H.; Liu, H.; Liu, T.; Li, C. A highly selective and stable $\mathrm{ZnO}-\mathrm{ZrO}_{2}$ solid solution catalyst for $\mathrm{CO}_{2}$ hydrogenation to methanol. Sci. Adv. 2017, 3, e1701290. [CrossRef] [PubMed]

84. Lopez-Ruiz, J.A.; Cooper, A.R.; Li, G.; Albrecht, K.O. Enhanced hydrothermal stability and catalytic activity of LaxZryOz mixed oxides for ketonization of acetic acid in the aqueous condensed phase. ACS Catal. 2017, 7,6400-6412. [CrossRef]

85. DuBois, J. Method for the Synthesis of Acrylonitrile from Glycerol. U.S. Patent 8,829,223, 9 September 2014.

86. Devaux, J.; DuBois, J. Process for Manufacturing Acrolein/Acrylonitrile. U.S. Patent 9,296,676, 29 March 2016.

87. Goyal, A. Compositions and Methods Related to the Production of Acrylonitrile. U.S. Patent 2016/0368861, 22 December 2016.

88. Karp, E.M.; Eaton, T.R.; Sànchez I Nogué, V.; Vorotnikov, V.; Biddy, M.J.; Tan, E.C.D.; Brandner, D.G.; Cywar, R.M.; Liu, R.; Manker, L.P.; et al. Renewable acrylonitrile production. Science 2017, 358, 1307-1310. [CrossRef] [PubMed]

89. Graselli, R.K.; Trifirò, F. Acrylonitrile from biomass: Still far from being a sustainable process. Top. Catal. 2016, 59. [CrossRef]

(C) 2018 by the author. Licensee MDPI, Basel, Switzerland. This article is an open access article distributed under the terms and conditions of the Creative Commons Attribution (CC BY) license (http://creativecommons.org/licenses/by/4.0/). 